\title{
Cryoglobulin Measurement
}

National Cancer Institute

\section{Source}

National Cancer Institute. Cryoglobulin Measurement. NCI Thesaurus. Code C111164.

The determination of the amount of cryoglobulin present in a sample. 